\title{
Phosphorylated AKT1 is associated with poor prognosis in esophageal squamous cell carcinoma
}

\author{
Zhengfei Zhu ${ }^{1,5 \dagger}$, Weiwei $\mathrm{Yu}^{2+}$, Xiaolong Fu, ${ }^{1,5^{*}}$, Menghong Sun ${ }^{3,5}$, Qiao Wei ${ }^{3,5}$, Dali Li ${ }^{3,5}$, Haiquan Chen ${ }^{4,5}$, \\ Jiaqing Xiang ${ }^{4,5}$, Hecheng Li $i^{4,5}$, Yawei Zhang ${ }^{4,5}$, Weixin Zhao ${ }^{1,5}$ and Kuaile Zhao ${ }^{1,5^{*}}$
}

\begin{abstract}
Background: The epidermal growth factor receptor (EGFR) signaling pathway is important in regulating biological behaviors in many malignancies. We explored whether expression and activation of EGFR and several components on its downstream pathways have prognostic significance in patients with esophageal squamous cell carcinoma (ESCC).

Methods: Expression of EGFR, phosphorylated (p)-EGFR, AKT1, p-AKT1, AKT2, p-AKT2, ERK1, ERK2, p-ERK1/2, STAT3, and p-STAT3 was assessed by immunohistochemical analysis of tissue microarrays for 275 ESCC patients who had undergone complete three-field lymphadenectomy. Spearman rank correlation tests were used to determine the relationships among protein expression, and Cox regression analyses were performed to determine the prognostic factors on overall survival (OS).

Results: p-EGFR expression was correlated statistically with all of the other phosphorylated markers. Gender, N stage, and p-AKT1 expression were found to be independent prognostic factors for OS. Increased expression of p-AKT1 was associated with decreased patient survival. EGFR and p-EGFR expression was not significantly associated with patient survival.
\end{abstract}

Conclusion: Activation of AKT1 was associated with poor prognosis in ESCC.

Keywords: Esophageal carcinoma, Esophageal squamous cell carcinoma, Epidermal growth factor receptor, p-AKT1, Prognostic factor, Prognosis, Immunohistochemistry

\section{Background}

Esophageal cancer (EC) is a common malignancy worldwide, with Asia being one of the high-prevalence areas [1]. Although the incidence rates for esophageal adenocarcinoma have been increasing in several Western countries, esophageal squamous cell carcinoma (ESCC) is the most common histological type in Eastern countries, such as China, where it accounts for more than $90 \%$ of EC cases [2]. Despite improvements in surgical techniques, perioperative management, and surgery combined with chemotherapy and/or radiotherapy, the

\footnotetext{
*Correspondence: xlfu1964@hotmail.com; kuaile_z@sina.com

Zhengfei Zhu, Weiwei Yu-both considered first author

†Equal contributors

'Department of Radiation Oncology, Fudan University Shanghai Cancer

Center, 270 Dong An Road, Shanghai 200032, China

Full list of author information is available at the end of the article
}

prognosis for ESCC remains poor, particularly in advanced stages [3]. Therefore, the development of new therapy modalities, particularly targeted therapies based on knowledge of the biology and genetics of the disease, may offer the potential for improving treatment response and quality of life for ESCC patients.

In the past decade, great interest has been directed toward the use of agents targeting cell surface receptors that are responsible for the development and progression of various cancers. Epidermal growth factor receptor (EGFR) is one of the most commonly altered receptors in human malignancies. This receptor is mainly involved in regulating cellular processes including cell apoptosis, proliferation, angiogenesis, migration, and adhesion through activation of PI3K-Akt, STAT3, and Ras-Raf-MAPK signaling pathways [4]. In a variety of human cancers, 
increased expression of EGFR has been identified and shown to be associated with advanced disease, development of metastases, and poor clinical prognosis in a subset of these cancers [5]. However, study results on the prognostic effect of EGFR in ESCC remain conflicting [6-10]. To investigate the role of EGFR-related pathway activities in ESCC progression, we used tissue microarray (TMA) technology and immunohistochemical (IHC) analysis to evaluate the activities of EGFR and its downstream effectors AKT, ERK, and STAT3 in ESCC; we also analyzed the relationships of these markers and their association with prognosis in ESCC patients.

\section{Materials and methods}

\section{Study population}

We have performed a series of studies to explore the clinical and biological prognostic factors in thoracic ESCC in patients who underwent complete three-field lymphadenectomy (3FLND) [11, 12]. We reviewed the pathology reports of all patients with EC who underwent 3FLND at our hospital between 2001 and 2009, and 354 patients were selected on the basis of the following clinical criteria: having pathologically confirmed thoracic ESCC; having only one primary tumor; not receiving preoperative chemotherapy and/or radiotherapy; having undergone 3FLND with $\geq 15$ total lymph nodes removed; and having tumor-free resection of margins by microscopic examination of the surgical specimen. Of these patients, 22 were excluded from analysis because of perioperative deaths ( 2 patients) and lost to follow-up (20 patients). Among the remaining 332 patients, paraffin specimens were not available for 57; thus, 275 patients were selected for this study.

The preoperative workup, surgical procedure, and criteria for adjuvant treatment and follow-up were described elsewhere $[11,12]$. The clinicopathologic characteristics of the study population are summarized in Table 1. This study was approved by the Institutional Review Board, which waived the requirement for written informed consent of individual patients, given the retrospective nature of this study.

\section{TMA construction and IHC analysis}

TMAs were constructed in collaboration with the Department of Pathology at our hospital according to established methods [13]. For each patient, the tumor was identified on the original hematoxylin and eosin-stained (H\&E) slides, and the corresponding formalin-fixed, paraffinembedded tissue blocks were obtained. With use of a UATM-272A Tissue Microarrayer (Unitma, Seoul, Korea), three 1-mm tissue cores which were punched from various areas of the predominant tumor population and one 1-mm normal tissue cone which were punched from the normal areas around tumor for each patient and deposited
Table 1 Clinicopathologic characteristics of 275 patients included in our study

\begin{tabular}{|c|c|}
\hline Characteristics & No. of patients (\%) \\
\hline \multicolumn{2}{|l|}{ Sex } \\
\hline Male & $223(81.1)$ \\
\hline Female & $52(18.9)$ \\
\hline \multicolumn{2}{|c|}{ Age (year) (36-78 year; median 57 year) } \\
\hline$\leq 60$ & $180(65.5)$ \\
\hline$<60$ & $95(34.5)$ \\
\hline \multicolumn{2}{|l|}{ Tumor location } \\
\hline Upper & $37(13.5)$ \\
\hline Middle & $175(63.6)$ \\
\hline Lower & $63(22.9)$ \\
\hline \multicolumn{2}{|l|}{ Tumor length } \\
\hline$<5 \mathrm{~cm}$ & $123(44.7)$ \\
\hline$\geq 5 \mathrm{~cm}$ & $152(55.3)$ \\
\hline \multicolumn{2}{|l|}{ Tumor differentiation } \\
\hline Well differentiated & $26(9.5)$ \\
\hline Moderately differentiated & $184(66.9)$ \\
\hline Poorly differentiated & $65(23.6)$ \\
\hline \multicolumn{2}{|l|}{ Pathologic T stage } \\
\hline $\mathrm{T} 1$ & $13(4.7)$ \\
\hline $\mathrm{T} 2$ & $100(36.4)$ \\
\hline T3 & $127(46.2)$ \\
\hline T4 & $35(12.7)$ \\
\hline \multicolumn{2}{|l|}{ Pathologic N stage } \\
\hline No & $101(36.7)$ \\
\hline N1 & $74(26.9)$ \\
\hline N2 & $71(25.8)$ \\
\hline N3 & $29(10.5)$ \\
\hline \multicolumn{2}{|l|}{ Pathologic TNM stage } \\
\hline I & $11(4.0)$ \\
\hline$\|$ & $120(43.6)$ \\
\hline III & $144(52.4)$ \\
\hline \multicolumn{2}{|l|}{ Adjuvant therapy } \\
\hline None & $106(38.5)$ \\
\hline Radiotherapy & $10(3.6)$ \\
\hline Chemotherapy & $83(30.2)$ \\
\hline Chemoradiotherapy & $50(18.2)$ \\
\hline Unknown & $26(9.5)$ \\
\hline
\end{tabular}

into a $12 \times 10$ TMA block (120 cores). IHC staining was performed on 4- $\mu \mathrm{m}$ paraffin-embedded sections from TMA blocks by the standard Envision method using a panel of antibodies: EGFR (113, dilution 1:50; Dako), AKT1 (C73H10, dilution $3 \mu \mathrm{g} / \mathrm{ml}$; Cell Signaling), AKT2 (302501, dilution $25 \mu \mathrm{g} / \mathrm{ml}$; R\&D), ERK1 (Y72, dilution 
1:100; Abcam), ERK2 (E460, dilution 1:250; Abcam), STA T3 (E121-21, dilution 1:50; Abcam), phosphorylated-EG FR (p-EGFR) (Tyr1068) (EP774Y, dilution 1:250; Abcam), phosphorylated-AKT1 (p-AKT1) (Ser473) (EP2109Y, dilution 1:100; Abcam), phosphorylated-AKT2 (p-AKT2) (Ser 474) (D3H2, dilution 1:100; Cell Signaling), phospho rylated-ERK1/2 (p-ERK1/2) (MAPK-YT, dilution 1:100; Abcam), and phosphorylated- STAT3 (p-STAT3) (EP2147 Y, dilution 1:250; Abcam) (Fig. 1).

\section{IHC scoring}

A modified semiquantitative method $\mathrm{H}$-score was used to evaluate IHC staining $[14,15]$. For each tissue core, a score was generated by multiplying the percentages of positive cells $(0-100 \%)$ and the intensity of staining. For EGFR and p-EGFR, the staining intensity was classified as follows: 0 , no staining; $1+$, partial membrane staining; $2+$, weak, complete membrane staining; $3+$, moderate, complete membrane staining; and 4+, strong, complete

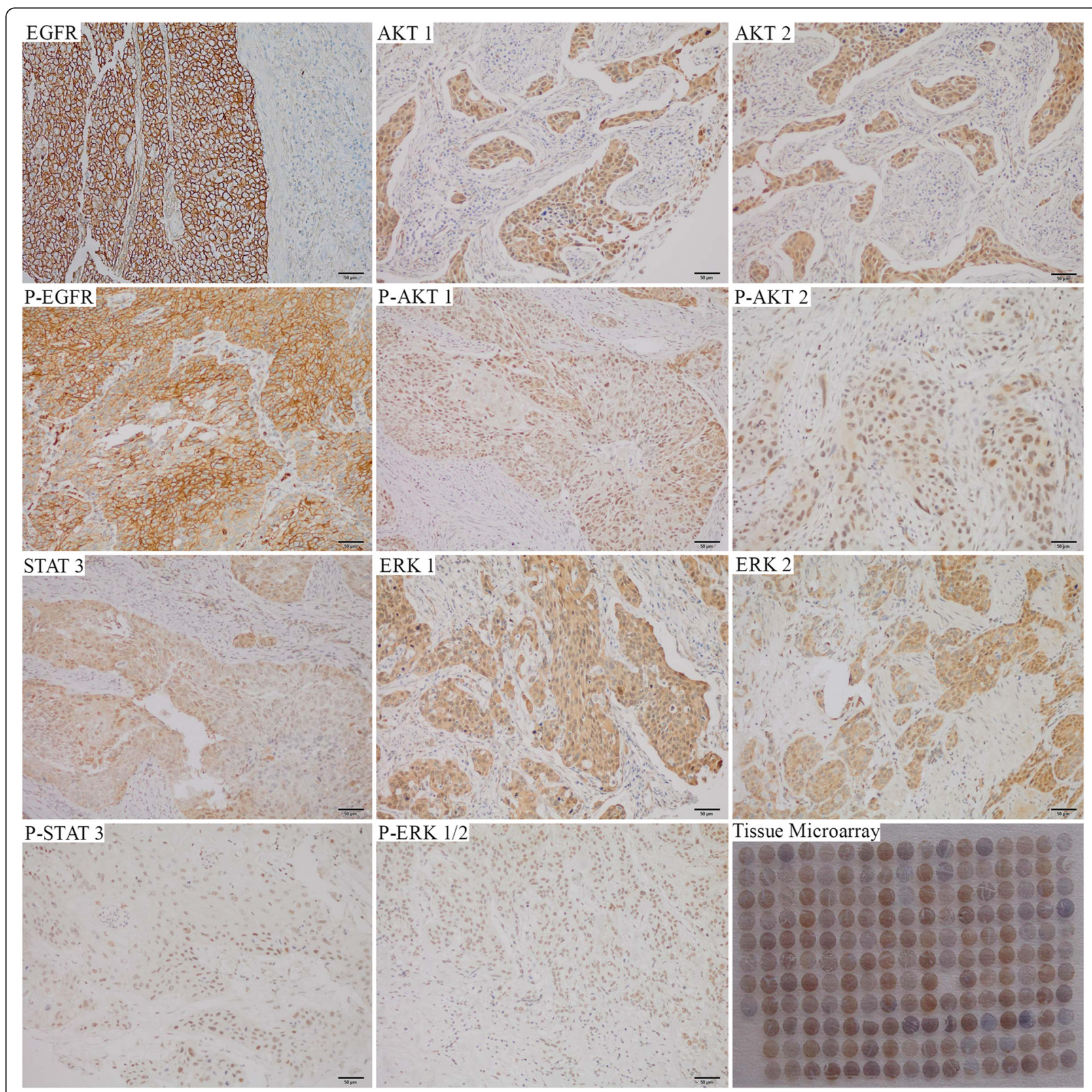

Fig. 1 Representative findings on immunohistochemical staining for the tested biomarkers (original magnification $\times 200$ ): EGFR, phosphorylated (p)-EGFR, AKT1, p-AKT1, AKT2, p-AKT2, ERK1, ERK2, p-ERK1/2, STAT3, and p-STAT3 
membrane staining. For the other markers, the staining intensity for IHC reaction was classified as follows: 0 , negative; $1+$, weak; $2+$, moderate; and $3+$, strong. Thus, the overall $\mathrm{H}$-score ranged from 0 to 400 (EGFR or pEGFR) or 0 to 300 (the other markers). All immunostains were evaluated independently by three pathologists and discordant cases were reevaluated; consensus was reached with use of a multiheaded microscope.

\section{Statistical analysis}

Continuous variables were summarized by descriptive statistics, such as means, standard deviations (SD), medians, and ranges. Categorical variables were tabulated by frequency and percentage. The survival functions were computed from the date of surgery by using Kaplan-Meier estimates, and the log-rank test was used to assess the equality of survival functions. Spearman rank correlation tests were used to assess the relationships among protein expression. Since there's at present no consensus which cut-off points were best for the markers we tested, we arbitrarily chose the median $\mathrm{H}$-score values as the cutpoints for the categorical analyses: the marker was considered high expression with the $\mathrm{H}$-score of $\geq$ the median value, and low expression with the $\mathrm{H}$-score of $<$ the median value. The univariate and multivariate Cox regression analyses were performed to test for the independent influence of potential prognostic factors on overall survival (OS). Probability (P) values $<0.05$ were considered statistically significant, and statistical tests were based on a two-sided significance level. Statistical analyses were performed with use of Statistical Package for the Social Sciences software (SPSS, Chicago, IL).

\section{Results}

\section{Correlation between EGFR expression and AKT, ERK and STAT3 in ESCC}

EGFR and p-EGFR staining were predominantly located in the cell membrane. AKT1, AKT2, ERK1, ERK2, and STAT3 immunoreactivity was mainly located in the cytoplasm. p-AKT1, p-AKT2, p-ERK1/2, and p-STAT3 expression was detected in both the cytoplasm and nucleus. Due to the inevitable loss of biopsy cores or insufficient tumor cells present in the cores, about 2-5 cases were missed for each marker staining. The patients who missed any data of marker staining were excluded, and left 270 patients for the final analysis. All of the marker expression results are summarized in Table 2.

Results from Spearman rank correlation analyses among EGFR, p-EGFR, p-AKT1, pAKT2, p-ERK1/2, and p-STAT3 showed that EGFR expression was correlated with that of p-EGFR $(P=0.001)$, p-AKT1 $(P<0.001)$ and p-AKT2 $(P<$ $0.001)$ but not with that of $\mathrm{p}$-ERK1/2 $(P=0.630)$ or $\mathrm{p}$ STAT3 $(P=0.835)$; -EGFR expression was correlated
Table 2 Expression of proteins in quartiles of $\mathrm{H}$-scores

\begin{tabular}{llllll}
\hline & Median & Minimum & Maximum & $25 \%$ & $75 \%$ \\
\hline EGFR & 80 & 0 & 400 & 0 & 160 \\
p-EGFR & 10 & 0 & 400 & 0 & 50 \\
AKT1 & 30 & 0 & 240 & 5 & 80 \\
p-AKT1 (Ser473) & 70 & 0 & 250 & 40 & 100 \\
AKT2 & 0 & 0 & 120 & 0 & 20 \\
p-AKT2 (Ser474) & 0 & 0 & 80 & 0 & 10 \\
ERK1 & 40 & 0 & 210 & 0 & 60 \\
ERK2 & 70 & 0 & 250 & 30 & 100 \\
p-ERK1/2 & 50 & 0 & 170 & 30 & 80 \\
STAT3 & 50 & 0 & 300 & 30 & 80 \\
p-STAT3 & 30 & 0 & 300 & 10 & 60 \\
\hline
\end{tabular}

statistically with that of p-AKT1 $(P<0.001)$, p-AKT2 $(P<$ $0.001)$, p-ERK1/2 $(P=0.027)$, and p-STAT3 $(P<0.001)$. pAKT1, p-AKT2, p-ERK1/2, and p-STAT3 expressions was correlated with each other except for that between p-AKT2 and p-ERK1/2 (Table 3).

\section{Clinical significance of phosphorylated-AKT1 in ESCC}

At a median follow-up time of 34 months (range: 2-125 months), the median OS for the entire cohort was 39 months (95\% confidence interval [CI]: 20-58 months), and survival rates were $52.5 \%$ at 3 years and $45.2 \%$ at 5 years (Fig. 2). The variables tested on univariate analysis showed that the factors that were significantly associated with OS included gender, $\mathrm{N}$ stage, adjuvant therapy, and expression of p-AKT1 (Table 4). On multivariate analysis, gender, $\mathrm{N}$ stage, and $\mathrm{p}-\mathrm{AKT} 1$ expression were found to be the independent prognostic factors for OS (Table 4). When expression of p-AKT1 increased, patients' survival duration decreased (HR: 2.682, 95 \% CI: 1.891-3.802). Log-rank tests of overall survival comparing patients with p-AKT1 high expression ( $\mathrm{H}$-scores $\geq 70)$ and those with p-AKT1 low expression $(\mathrm{H}$-scores $<70)$ show that the group with p-AKT1 low expression had significantly better OS than did the group with high expression among all patients $(P<0.001$, Fig. 3a), patients with stage I-II diease $(P<0.001$, Fig. $3 \mathrm{~b})$ and patients with stage III disease $(P<0.001$, Fig. $3 c)$.

\section{Discussion}

In this study, we tested the protein expression and activities of EGFR as well as several key nodes on its downstream pathways for ESCC patients and found that expression of p-AKT1, p-AKT2, p-ERK1/2, and p-STAT3 was significantly related to the expression of p-EGFR. We also found that activation of AKT1 independently influenced patients' survival, with higher expression of p-AKT1 being linked to poorer OS; neither EGFR nor p-EGFR 
Table 3 Correlations of the protein expression: Spearman rank correlation tests

\begin{tabular}{|c|c|c|c|c|c|c|c|}
\hline & & EGFR & $p$-EGFR & p-AKT1 & p-AKT2 & $p$-ERK1/2 & p-STAT3 \\
\hline \multirow[t]{2}{*}{ EGFR } & Correlation coefficient & 1.000 & 0.196 & 0.269 & 0.226 & -0.030 & 0.013 \\
\hline & $P$ value & . & 0.001 & $<0.001$ & $<0.001$ & 0.630 & 0.835 \\
\hline \multirow[t]{2}{*}{$p$-EGFR } & Correlation coefficient & 0.196 & 1.000 & 0.337 & 0.331 & 0.135 & 0.390 \\
\hline & $P$ value & 0.001 & . & $<0.001$ & $<0.001$ & 0.027 & $<0.001$ \\
\hline \multirow[t]{2}{*}{ p-AKT1 } & Correlation coefficient & 0.269 & 0.337 & 1.000 & 0.355 & 0.127 & 0.219 \\
\hline & $P$ value & $<0.001$ & $<0.001$ & & $<0.001$ & 0.038 & $<0.001$ \\
\hline \multirow[t]{2}{*}{ p-AKT2 } & Correlation coefficient & 0.226 & 0.331 & 0.355 & 1.000 & 0.018 & 0.180 \\
\hline & $P$ value & $<0.001$ & $<0.001$ & $<0.001$ & & 0.772 & 0.003 \\
\hline \multirow[t]{2}{*}{ p-ERK1/2 } & Correlation coefficient & -0.030 & 0.135 & 0.127 & 0.018 & 1.000 & 0.204 \\
\hline & $P$ value & 0.630 & 0.027 & 0.038 & 0.772 & . & 0.001 \\
\hline \multirow[t]{2}{*}{ p-STAT3 } & Correlation coefficient & 0.013 & 0.390 & 0.219 & 0.180 & 0.204 & 1.000 \\
\hline & $P$ value & 0.835 & $<0.001$ & $<0.001$ & 0.003 & 0.001 & \\
\hline
\end{tabular}

expression, however, had a prognostic effect in ESCC patients in this cohort.

Currently, the role of EGFR in tumor development in ESCC is not clear, although elevated expression of EGFR has been reported in 50-90\% of patients with ESCC [16-20]. Several studies have shown that EGFR overexpression was associated with poor OS and poor disease-free survival in ESCC patients [6-8]; other studies, however, did not find a prognostic effect for EGFR overexpression in ESCC $[9,10]$. The inconsistent conclusions drawn from the various studies might be due to differences in patient selection, treatments, and the methods used for detecting and scoring EGFR expression.

In the present study, the prognostic value of EGFR was not found. Several researchers $[9,21]$ have reported

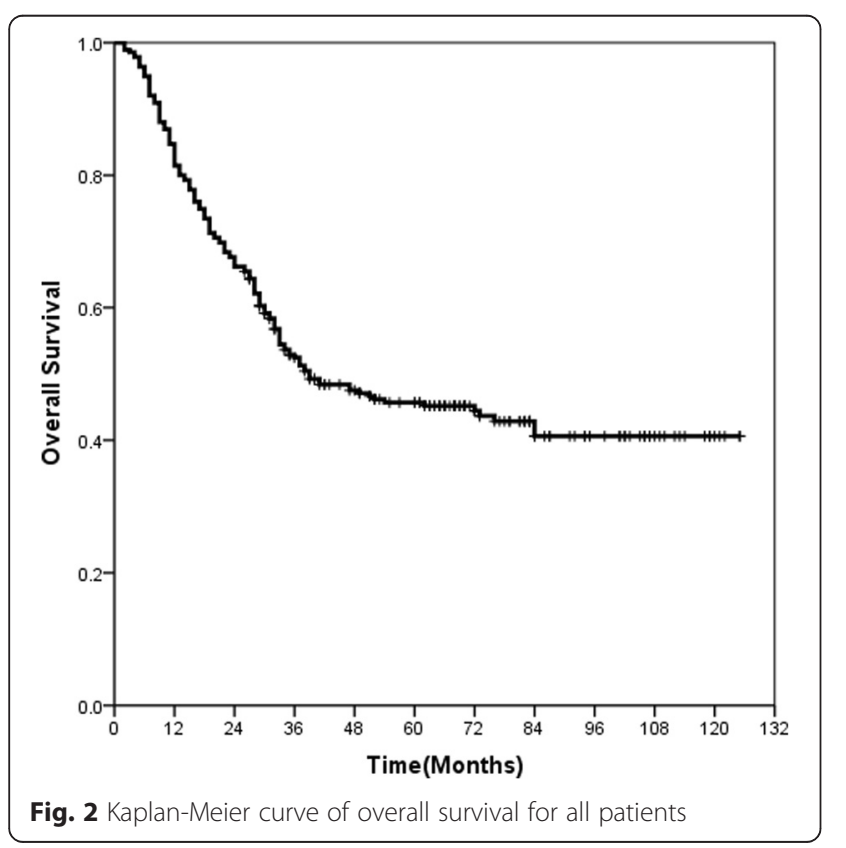

that EGFR expression has predictive value for the therapeutic effect of chemotherapy and radiotherapy in ESCC; specifically, patients with elevated EGFR expression had better treatment outcomes after chemoradiotherapy. To rule out the influence of adjuvant chemotherapy and/or radiotherapy in the prognosis, we performed Cox regression analyses for the 106 patients who did not receive adjuvant therapy in our group and still found no association between EGFR expression and OS (data not shown). Our future work will explore whether alterations of EGFR, including gene mutation and amplification, have prognostic values in ESCC.

EGFR is a tyrosine kinase receptor, and the phosphorylated tyrosine residue serves as a docking site to exert its biological roles. After being phosphorylated, EGFR is activated and then in turn activates multiple downstream intracellular signaling pathways, mainly PI3KAkt, STAT3, and Ras-Raf-MAPK pathways. Our finding that p-EGFR was highly correlated to the phosphorylation of AKT1, AKT2, ERK1/2, and STAT3 indicated that p-EGFR possibly contributed to the activation of these downstream pathways in ESCC, suggesting that the EGFR pathways might be active in some patients with ESCC. However, we also observed that p-AKT1 could predict the prognosis of ESCC, while EGFR and p-EGFR could not be, suggesting that the activation of AKT1 resulted from other factors in some patients. Besides EGFR stimulation, several other ways of activating AKT1 have been reported, including other growth factor receptors such as VEGF and PDGF, mutations of PI3K or RAS, inactivation of tumor suppressor gene PTEN, and AKT1 ${ }^{\text {E17K }}$ somatic mutations [22-26]. The exact mechanisms of this phenomenon in ESCC are unclear and need further investigation.

$\mathrm{AKT}$, a serine/threonine protein kinase, is the central mediator of the canonical PI3K pathway, which can mediate various cellular functions including cell 
Table 4 Univariate and multivariate for overall survival: Cox proportional hazards regression model

\begin{tabular}{|c|c|c|c|}
\hline \multirow[t]{3}{*}{ Prognostic factors } & \multicolumn{3}{|l|}{ OS } \\
\hline & $P$ value & $P$ value & $\mathrm{HR}(95 \% \mathrm{Cl})$ \\
\hline & (univariate) & (multivariate) & (for multivariate) \\
\hline Sex (male, female) & 0.011 & 0.012 & $1.346(1.071-1.803)$ \\
\hline Age $(\leq 60,>60$ year $)$ & 0.373 & & \\
\hline Tumor location (upper, middle, lower) & 0.277 & & \\
\hline Tumor length $(<5 \mathrm{~cm}, \geq 5 \mathrm{~cm})$ & 0.890 & & \\
\hline Tumor differentiation (well, moderately, poorly) & 0.148 & & \\
\hline T stage $(T 1, T 2, T 3, T 4)$ & 0.128 & & \\
\hline $\mathrm{N}$ stage $(\mathrm{N} 0, \mathrm{~N} 1, \mathrm{~N} 2, \mathrm{~N} 3)$ & $<0.001$ & $<0.001$ & \\
\hline NO & & & 1 \\
\hline N1 & & & $1.875(1.187-2.962)$ \\
\hline N2 & & & $3.646(2.355-5.645)$ \\
\hline N3 & & & $2.444(1.387-4.307)$ \\
\hline Adjuvant therapy (none, chemotherapy, radiotherapy, chemoradiotherapy, unknown) & 0.027 & & \\
\hline EGFR $(\geq 80,<80)$ & 0.735 & & \\
\hline$p-E G F R(\geq 10,<10)$ & 0.392 & & \\
\hline AKT1 $(\geq 30,<30)$ & 0.362 & & \\
\hline p-AKT1 $(\geq 70,<70)$ & $<0.001$ & $<0.001$ & $2.682(1.891-3.802)$ \\
\hline $\operatorname{AKT} 2(>0,=0)$ & 0.179 & & \\
\hline $\mathrm{p}-\mathrm{AKT} 2(>0,=0)$ & 0.379 & & \\
\hline ERK1 $(\geq 40,<40)$ & 0.683 & & \\
\hline ERK2 $(\geq 70,<70)$ & 0.558 & & \\
\hline $\mathrm{p}-\mathrm{ERK} 1 / 2(\geq 50,<50)$ & 0.209 & & \\
\hline STAT3 $(\geq 50,<50)$ & 0.233 & & \\
\hline p-STAT3 $(\geq 30,<30)$ & 0.621 & & \\
\hline
\end{tabular}

$\mathrm{HR}$, hazard ratio; $\mathrm{Cl}$, confidence interval; $\mathrm{OS}=$ overall survival
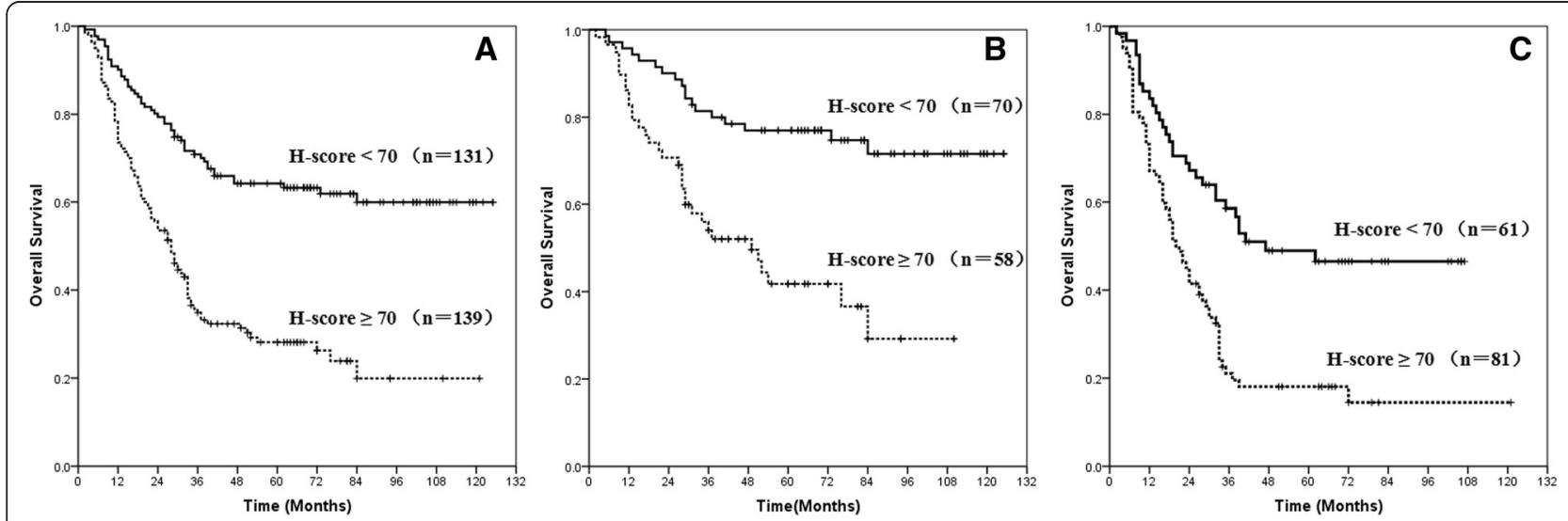

Fig. 3 Log-rank tests of overall survival comparing patients with p-AKT1 $\mathrm{H}$-scores of $\geq 70$ and those with $\mathrm{p}$-AKT1 $\mathrm{H}$-scores of $<70$ for (a) all patients $(n=270 ; P<0.001)$; b stage I-II patients $(n=128 ; P<0.001)$; and $\mathbf{c}$ stage III patients $(n=142 ; P<0.001)$ 
metabolism, growth, proliferation, survival, apoptosis, and angiogenesis [27]. A number of studies have demonstrated the overactivation of AKT in many human solid tumors and hematological malignancies [28]. AKT has three isoforms: AKT1, AKT2, and AKT3. Although these AKT family members share a similar domain structure, they have distinct substrates and different physiological behaviors [29]. These AKT isoforms seem to mediate different functions in cancer pathophysiology; for example, AKT1 appears to promote mammary tumor induction, whereas AKT2 promotes metastasis in previous reports $[29,30]$. This may explain the difference in the prognostic effects between p-AKT1 and p-AKT2 in ESCC patients in our study.

The prognostic values of p-AKT1 have been studied for several malignancies. Interestingly, many studies have shown that activation of AKT1 was associated with poor prognosis [31-33], whereas other studies have shown AKT1 activation to be a favorable prognostic indicator [34-36]. To the best of our knowledge, few studies have examined the association between AKT1 activation and clinical outcome in ESCC. Yoshioka et al. [37] used IHC analysis to examine p-AKT expression in 235 ESCC patients who underwent surgery with or without preoperative chemotherapy and found that p-AKT expression was associated with poor prognosis in those who had received chemotherapy but did not correlate with survival in those who had not received chemotherapy. However, that study did not specify the isoform of AKT1. Nowadays, the PI3K/AKT pathway has been recognized as an important pathway in the development of cancers [38]. Our study suggested the potential of AKT1 as a target for anticancer therapeutics in ESCC.

\section{Conclusion}

Our study suggests p-AKT1 is associated with poor prognosis in patients with ESCC, and supports further studies to investigate the potential mechanisms.

\footnotetext{
Abbreviations

EC: Esophageal cancer; ESCC: Esophageal squamous cell carcinoma; EGFR: Epidermal growth factor receptor; TMA: Tissue microarray; IHC: Immunohistochemical; 3FLND: Three-field lymphadenectomy; H\&E: Hematoxylin and eosin-stained; p-EGFR: Phosphorylated-EGFR; p-AKT1: Phosphorylated-AKT1; p-AKT2: Phosphorylated-AKT2; p-ERK1/ 2: Phosphorylated-ERK1/2; p-STAT3: Phosphorylated- STAT3; SD: Standard deviations; OS: Overall survival; Cl: Confidence interval.
}

\section{Competing interests}

The authors declare that they have no competing interests.

\section{Authors' contributions}

KLZ, XLF, ZZF and WWY conceived and designed the study. ZZF, WWY, MHS, QW and DLL performed the experiments. ZZF, WWY and DLL analyzed the data. HCC, JXX, HCL, YWZ and WXZ contributed reagents/materials/analysis tools. ZZ and WY wrote the paper. ZZF, WWY, XLF, MHS, QW, DLL, HQC, JXX, $H C L, Y W Z, W X Z$ and KLZ read and revised the manuscript, accepted the final version. All authors read and approved the final manuscript.

\section{Acknowledgments}

We thank the Department of Scientific Publication at The University of Texas MD Anderson Cancer Center for editorial review of this paper. This work was sponsored by the Scientific Research Foundation for the Returned Overseas Chinese Scholars, State Education Ministry, and Foundation of Shanghai Municipal Commission of Health and Family Planning, and partially supported by Shanghai Committee of Science and Technology, Natural Science Foundation of Shanghai, China (NO.11ZR1407300).

\section{Author details}

'Department of Radiation Oncology, Fudan University Shanghai Cancer Center, 270 Dong An Road, Shanghai 200032, China. ${ }^{2}$ Department of Radiation Oncology, Six Hospital of Jiao Tong University, Shanghai, China. ${ }^{3}$ Department of Pathology, Fudan University Shanghai Cancer Center, Shanghai, China. ${ }^{4}$ Department of Thoracic Surgery, Fudan University Shanghai Cancer Center, Shanghai, China. ${ }^{5}$ Department of Oncology, Shanghai Medical College, Fudan University, 270 Dong An Road, Shanghai 200032, China.

Received: 11 May 2015 Accepted: 25 August 2015

Published online: 04 September 2015

\section{References}

1. Ferlay J, Shin HR, Bray F, Forman D, Mathers C, Parkin DM. Estimates of worldwide burden of cancer in 2008: GLOBOCAN 2008. Int J Cancer. 2010;127:2893-917.

2. Jemal A, Bray F, Center MM, Ferlay J, Ward E, Forman D. Global cancer statistics. CA Cancer J Clin. 2011;61:69-90.

3. Nakajima M, Kato H. Treatment options for esophageal squamous cell carcinoma. Expert Opin Pharmacother. 2013;14:1345-54.

4. Seshacharyulu P, Ponnusamy MP, Haridas D, Jain M, Ganti AK, Batra SK. Targeting the EGFR signaling pathway in cancer therapy. Expert Opin Ther Targets. 2012;16:15-31.

5. Herbst RS. Review of epidermal growth factor receptor biology. Int J Radiat Oncol Biol Phys. 2004;59:21-6.

6. Wang KL, Wu TT, Choi IS, Wang H, Resetkova E, Correa AM, et al. Expression of epidermal growth factor receptor in esophageal and esophagogastric junction adenocarcinomas: association with poor outcome. Cancer. 2007;109:658-67.

7. Wilkinson NW, Black JD, Roukhadze E, Driscoll D, Smiley S, Hoshi H, et al. Epidermal growth factor receptor expression correlates with histologic grade in resected esophageal adenocarcinoma. J Gastrointest Surg. 2004;8:448-53.

8. Hoshino M, Fukui H, Ono Y, Sekikawa A, Ichikawa K, Tomita S, et al. Nuclear expression of phosphorylated EGFR is associated with poor prognosis of patients with esophageal squamous cell carcinoma. Pathobiology. 2007;74:15-21.

9. Gotoh M, Takiuchi H, Kawabe S, Ohta S, Kii T, Kuwakado S, et al. Epidermal growth factor receptor is a possible predictor of sensitivity to chemoradiotherapy in the primary lesion of esophageal squamous cell carcinoma. Jpn J Clin Oncol. 2007;37:652-7.

10. Kii T, Takiuchi H, Kawabe $S$, et al. Evaluation of prognostic factors of esophageal squamous cell carcinoma (stage II-III) after concurrent chemoradiotherapy using biopsy specimens. Jpn J Clin Oncol. 2007;37:583-9.

11. Zhu Z, Yu W, Li H, Zhao K, Zhao W, Zhang Y, et al. Nodal skip metastasis is not a predictor of survival in thoracic esophageal squamous cell carcinoma. Ann Surg Oncol. 2013;20:3052-8.

12. Zhu Z, Chen H, Yu W, Fu X, Xiang J, Li H, et al. Number of negative lymph nodes is associated with survival in thoracic esophageal squamous cell carcinoma patients undergoing three-field lymphadenectomy. Ann Surg Oncol. 2014;21:2857-63.

13. Xiao X, Wang L, Wei P, Chi Y, Li D, Wang Q, et al. Role of MUC20 overexpression as a predictor of recurrence and poor outcome in colorectal cancer. J Transl Med. 2013;11:151

14. Skliris GP, Hube F, Gheorghiu I, Mutawe MM, Penner C, Watson PH, et al Expression of small breast epithelial mucin (SBEM) protein in tissue microarrays (TMAs) of primary invasive breast cancers. Histopathology. 2008;52:355-69.

15. Hirsch FR, Dziadziuszko R, Thatcher N, Mann H, Watkins C, Parums DV, et al. Epidermal growth factor receptor immunohistochemistry: comparison of 
antibodies and cutoff points to predict benefit from gefitinib in a phase 3 placebo-controlled study in advanced nonsmall-cell lung cancer. Cancer. 2008;112:1114-21.

16. Hanawa M, Suzuki S, Dobashi Y, Yamane T, Kono K, Enomoto N, et al. EGFR protein overexpression and gene amplification in squamous cell carcinomas of the esophagus. Int J Cancer. 2006;1 18:1173-80.

17. Sunpaweravong $P$, Sunpaweravong S, Puttawibul P, Mitarnun W, Zeng C, Barón AE, et al. Epidermal growth factor receptor and cyclin D1 are independently amplified and overexpressed in esophageal squamous cell carcinoma. J Cancer Res Clin Oncol. 2005:131:111-9.

18. Yamazaki M, Yamashita Y, Kubo N, Yashiro M, Ohira M, Ako E, et al. Concurrent biological targeting therapy of squamous cell carcinoma of the esophagus with cetuximab and trastuzumab. Oncol Rep. 2005;28:49-54.

19. Gibault L, Metges JP, Conan-Charlet V, Lozac'h P, Robaszkiewicz M, Bessaguet $C$, et al. Diffuse EGFR staining is associated with reduced overall survival in locally advanced oesophageal squamous cell cancer. Br J Cancer. 2005;93:107-15.

20. Wei Q, Chen L, Sheng L, Nordgren H, Wester K, Carlsson J. EGFR, HER2 and HER3 expression in esophageal primary tumours and corresponding metastases. Int J Oncol. 2007;31:493-9.

21. Yamamoto Y, Yamai H, Seike J, Yoshida T, Takechi H, Furukita Y, et al. Prognosis of esophageal squamous cell carcinoma in patients positive for human epidermal growth factor receptor family can be improved by initial chemotherapy with docetaxel, fluorouracil, and cisplatin. Ann Surg Oncol. 2012;19:757-65.

22. Yuan TL, Cantley LC. PI3K pathway alterations in cancer: variations on a theme. Oncogene. 2008:27:5497-510.

23. Carpten JD, Faber AL, Horn C, Donoho GP, Briggs SL, Robbins CM, et al. A transforming mutation in the pleckstrin homology domain of AKT1 in cancer. Nature. 2007:448:439-44.

24. Bleeker FE, Felicioni L, Buttitta F, Lamba S, Cardone L, Rodolfo M, et al. AKT1(E17K) in human solid tumours. Oncogene. 2008;27:5648-50.

25. Malanga D, Scrima M, De Marco C, Fabiani F, De Rosa N, De Gisi S, et al. Activating E17K mutation in the gene encoding the protein kinase AKT1 in a subset of squamous cell carcinoma of the lung. Cell Cycle. 2008;7:665-9.

26. Davies MA, Stemke-Hale K, Tellez C, Calderone TL, Deng W, Prieto VG, et al. A novel AKT3 mutation in melanoma tumours and cell lines. Br J Cancer. 2008:99:1265-8.

27. Manning BD, Cantley LC. AKT/PKB signaling: navigating downstream. Cell. 2007;129:1261-74

28. Altomare DA, Testa JR. Perturbations of the AKT signaling pathway in human cancer. Oncogene. 2005;24:7455-64.

29. Veeriah S. Opposing roles of the oncogene Akt isoforms in tumour progression: is there a dark side to Akt pathway inhibition? J Chem Biol. 2012:5:115-7.

30. Dillon RL, Marcotte R, Hennessy BT, Woodgett JR, Mills GB, Muller WJ. Akt1 and akt2 play distinct roles in the initiation and metastatic phases of mammary tumor progression. Cancer Res. 2009;69:5057-64.

31. Kreisberg Jl, Malik SN, Prihoda TJ, Bedolla RG, Troyer DA, Kreisberg S, et al. Phosphorylation of Akt (Ser473) is an excellent predictor of poor clinical outcome in prostate cancer. Cancer Res. 2004;64:5232-6.

32. Schlieman MG, Fahy BN, Ramsamooj R, Beckett L, Bold RJ. Incidence, mechanism and prognostic value of activated AKT in pancreas cancer. Br J Cancer. 2003;89:2110-5.

33. Dai DL, Martinka M, Li G. Prognostic significance of activated Akt expression in melanoma: a clinicopathologic study of 292 cases. J Clin Oncol. 2005;23:1473-82

34. Shah A, Swain WA, Richardson D, Edwards J, Stewart DJ, Richardson CM, et al. Phospho-akt expression is associated with a favorable outcome in non-small cell lung cancer. Clin Cancer Res. 2005;11:2930-6.

35. Baba Y, Nosho K, Shima K, Hayashi M, Meyerhardt JA, Chan AT, et al. Phosphorylated AKT expression is associated with PIK3CA mutation, low stage, and favorable outcome in 717 colorectal cancers. Cancer. 2011;117:1399-408.

36. Javle MM, Yu J, Khoury T, Chadha KS, Iyer RV, Foster J, et al. Akt expression may predict favorable prognosis in cholangiocarcinoma. J Gastroenterol Hepatol. 2006;21:1744-51.

37. Yoshioka A, Miyata H, Doki Y, Yasuda T, Yamasaki M, Motoori M, et al. The activation of Akt during preoperative chemotherapy for esophageal cancer correlates with poor prognosis. Oncol Rep. 2008;19:1099-107.

38. Courtney KD, Corcoran RB, Engelman JA. The PI3K pathway as drug target in human cancer. J Clin Oncol. 2010;28:1075-83.

\section{Submit your next manuscript to BioMed Central and take full advantage of:}

- Convenient online submission

- Thorough peer review

- No space constraints or color figure charges

- Immediate publication on acceptance

- Inclusion in PubMed, CAS, Scopus and Google Scholar

- Research which is freely available for redistribution

Submit your manuscript at www.biomedcentral.com/submit 